\title{
ADRIANA CAROLINA BULZ
}

\author{
Running Water* \\ * Has No Memory \\ The Grove 20 (2012)
}

I am no longer trickling up the wall!

Seeping in the dark, bubling in the sun, I am still striving to fill up my course,

So I keep running

With no solid memory on my shores

Except for a faint foreignizing whistlebow.

Within immemorable distance from my source

I am confined to leaking through the pipelines

Where I unravel my feelings up to bursting point.

Letting these loose,

I solidify into hopes, and rage, and remorse

But never regret my aching ripples.

(Having no body I cherish the traces of pain

Inflicted upon my reflection at which I smile so often.)

I wish now I were a drop in this quivering turbid pond!

At least its borders recall how grassy roots used to tickle [its insole

While my waves travel constantly to their underneath [repose.

How can I grow old when I have no regrets?

Still there is memory in the great outside (I believe in my heart that roots may still breath From underneath a concrete layer). Here I am:

My face a blank stare colored with clouds and creased

[by sparrows,

Blushing at sunset and turning purple with the stars, Floating ever so stealthily and filled with resilience In my watery bed. 
Fishermen love me for the silvery cues I provide And sing to me daily whirring their rods with knotty [fingers

While I undo my wishbones.

As the noon sinks its rays vertically into my chest I feel like leaping towards the riverbanks to unfurl Mermaid-like tresses for the occasional pedestrian.

I am most resigned by early morning, when ink-blue [shades

Dip their misteries into my foam. Then I receive any [stranger coily,

With a smug assent. I could spell the names of all those [whose image I embraced

Were I not sworn to silence by my own

Monolithic passage.

I don't overindulge in personal thoughts

(these here express a mere fad once upon an afternoon) So I wish you well, my enemy's children, and may you in my restlessness forevermore! [delight Your sweet-watered foe 